\title{
Addressing core questions from parents of children who stutter
}

\author{
Brent Andrew Gregg \\ Department of Communication Sciences and Disorders, University of Central Arkansas, Conway, Arkansas, USA
}

Purpose: The focus on parent counseling following the initial evaluation of young children who stutter is not a new direction. The purpose of this article is to summarize core components regarding addressing the questions of parents of children who stutter.

Methods: This analysis of scientific literature provides a guide to responding to these principal questions about childhood stuttering using research data and counseling methods.

Results: Given the breadth and depth of the past literature in this area, it is important to understand that the therapeutic relationship with the family of a preschooler who stutters begins at the initial evaluation. As a result, clinicians should work to achieve a dialogue that strikes a balance of encouraging parents to take proper action, easing irrational fears, and instilling hope of realistic, positive communication results.

Conclusions: Achieving an equilibrium of motivation and assuredness during these tough conversations warrants skills in counseling-based approaches.

Keywords: Stuttering, Counseling, Persistence, Recovery, Parents

\section{INTRODUCTION}

Many preschool-aged children exhibit periods of disfluency as they learn to navigate the linguistic world. Some of these children will experience mild stuttering, and for others, the difficulty will become more severe. Knowing the difference between normal developmental speech disfluency and potentially chronic stuttering enables a professional to advise parents and refer when appropriate. Moreover, parent counseling during this critical period can help to alleviate guilt and anxious feelings the parents may have.

The focus on parent counseling following the initial evaluation of young children who stutter is not a new direction. It is well-known that Johnson's [1,2] initial advice to parents consisted of sharing information on speech development, the normalcy of disfluencies, and the causes of stuttering, according to Johnson's own theory. Other early practitioners focused the initial evaluation session on altering the parents' perceptions and attitudes so as to promote in the child a strong feeling of acceptance [3], and recommended creating a favorable and consistent environment for fluency so that maturation and stabilization of the communication system can take place [4]. Additional writing about and programs for advising parents of preschool age children who stutter, sometimes as components in more comprehensive treatment programs, have continued to appear with some variations in orientation, general structure, and step-by-step

\section{(c)}
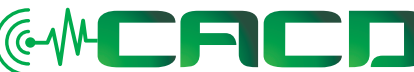

Received: January 29, 2020

Revision: May 2, 2020

Accepted: May 4, 2020

Correspondence:

Brent Andrew Gregg

Department of Communication Sciences and Disorders, University of Central

Arkansas, Conway, Arkansas 72034, USA

Tel: +1-501-852-2823

Fax: +1-501-450-5474

E-mail: bgregg@uca.edu

(C) 2020 The Korean Association of SpeechLanguage Pathologists

This is an Open Access article distributed under the terms of the Creative Commons Attribution NonCommercial License (https://creativecommons.org/ licenses/by-nc/4.0/) which permits unrestricted noncommercial use, distribution, and reproduction in any medium, provided the original work is properly cited. 
details [5-8]. These programs appear to reflect not only past thinking but also significant portions of current practices in advising parents throughout the therapeutic process.

Given the breadth and depth of the past literature in this area, however, it is important to understand that the therapeutic relationship with the family of a preschooler who stutters begins at the initial evaluation.

It is during these initial meetings with pediatricians and speech-language pathologists that parents of children who stutter tend to raise a core set of important questions: What caused it? How long will it last? Will it go away? What can be done to help? As experts in the domain of stuttering, speechlanguage pathologists have a responsibility to address these questions with evidence-based information that facilitates good parental decision making for the best clinical outcome. Clinicians should work to achieve a dialogue that strikes a balance of encouraging parents to take proper action, easing irrational fears, and instilling hope of realistic, positive communication results. Achieving equilibrium of motivation and assuredness during these tough conversations warrants skills in counseling-based approaches. The following is a guide to responding to these principal questions about childhood stuttering using research data and counseling methods.

For parents, receiving information regarding their child's stuttering can bring about a variety of negative emotions. Among them, Manning [9] specifically discusses grief, inadequacy, anger, guilt, vulnerability, and confusion as being typical reactions found in parents of children who stutter. Manning explains that some parents may go through feelings of grief at the onset of stuttering, as it is potentially the loss of their child's fluent communication. Some parents experience feelings of inadequacy when they feel like they do not have the knowledge or skills on their own to "fix" their child's stuttering. Additionally, many clinicians report that parents of children who stutter can go through periods of anger, as the presence of stuttering brings about a violation of expectations and/or a loss of control. Guilt may be felt by parents as they find out more information about their child's stuttering, such as how environmental pressures can impact stuttering can cause parents to feel bad about not seeking help sooner, "failing" to identify the problem early enough, or genetically "passing on" their problem to their children. Feelings of vulnerability and confusion often are reported by parents, particularly in navigating how to appropriately react to their child's stuttering and in trying to understand the complexity of the disorder and the steps needed to reach the best outcome.

\section{Orientation of the counselor}

When taking on the task of a stuttering consultation, a clinician is entering into a role-even if brief-of informer and counselor with the parents. Rogers [10] described the three basic conditions of the counseling relationship: congruence, unconditional positive regard, and empathetic understanding. Congruence, or transparency, refers to being open and honest with parents, a major step for clinicians in establishing trust with the parent. Unconditional positive regard refers to the valuation of the parents for who they are without judgment. Though it can be easy to scoff at parents' harsh reactions to their child's stuttering, adherence to unsubstantiated views about the cause of their child's stuttering, sloth in attaining help for their child, or their perceived stubbornness for taking the proper steps in managing their child's care, it is important that clinicians avoid judgment of parents and strive for a relationship of mutual respect with parents. Empathetic understanding means staying focused and attuned to the parent's feelings as possible. Finding empathetic understanding with parents warrants listening to and actively trying to understand their needs.

\section{"What caused it?"}

In this information age where parents have access to an abundance of material online, it is vital that the speech-language pathologist serve as a reliable source of information and director to proper resources. Many times, we are confronted with situations where parents have received erroneous or misleading information from a variety of sources, such as friends, a pediatrician, or the internet. It is therefore the responsibility of the clinician to dispel any myths or inaccuracies held by the child's parents/caregivers. A confidence in the manner in which this information is delivered, of course, takes time and practice. When it comes to finding information about the etiology of stuttering, this need for filtering of evidence-based information is especially vital. Parents likely will encounter a variety of answers to the etiology question, even when searching among publications from within our field. It is important that parents know the main answer to the ageold "what caused it" inquiry up front: we do not know. Letting parents know initially that the etiology of stuttering is unknown helps them to become better consumers of the evidence-based information about research that supports various causes, empowering them to filter these theories as critical thinkers. 


\section{THEORETICAL EXPLANATIONS}

Discussing theories of stuttering with parents can help serve two purposes: 1) it can make parents feel like the clinician is well-informed when the speech-language pathologist raises topics that they have researched or heard about, 2) it can alleviate any feelings of foolishness that parents had about subscribing to any of these theories known that each was once part of the zeitgeist of the field. Clinicians may choose to address a variety of popular theoretical explanations of stuttering from incomplete cerebral dominance from switching a child's handedness [11], to neuromotor deficits [12], to covert repairs of anticipated articulation errors [13], to the speed of speech exceeding phonological encoding [14], to stuttering as a byproduct of repairs of unusual speech processes [15]. Moving past these older views of stuttering, it is then important to present newer explanations for stuttering supported by more current research, particularly in the domains of neuroimaging and genetics [16]. Finally, it is important that parents come to understand that no single etiologic theory has been proven, because stuttering is a multidimensional disorder.

\section{Multidimensional models}

Stuttering is best understood from a multidimensional perspective. People who stutter comprise a heterogeneous group with variability as being the most prominent feature of stuttering according to Starkweather [17]. The following are multidimensional models in which to frame stuttering. Zimmerman [18] was one of the first in our field to propose a multidimensional model of stuttering, suggesting that stuttering was the result of disruption in the coordination of respiratory, phonatory, and articulatory processes for speech. His hypothesis was that people who stutter have variable motor skills and lower thresholds in disruption to motor speech control. Another multidimensional model of stuttering etiology was proposed by Wall and Meyers [19], who hypothesized that stuttering stems from interactions among psycholinguistic, psychosocial, and physiological components with the impact of one factor superseding the impact of the other two factors or functioning independently.

The Demands and Capacities Model proposed that the onset and development of stuttering is related to a mismatch between a child's capacities (motor, linguistic, cognitive, and emotional) and the self-imposed demands or externally driven speech demands (time pressure, pragmatic issues, and situational influences). If the capacities match the speech per- formance, the child will be fluent; if demands exceed capacities, dysfluencies will result. Smith and De Nil [20] hypothesized that stuttering stems from the interaction of physiological processes with emotional, social, and learned factors. Smith views stuttering behavior is the end product of multiple antecedent events. The patient's motor system functions along a continuum of stability and the level of stability in motor speech output, making stuttering vary across time in each person. De Nil [20] proposes that stuttering is a manifestation of physiological processing related to three processing levels. The interactions of these three levels cause stuttering to be variable across time: central neurophysiological processing, observable behavior (associated with motor, cognitive, linguistic, social, and emotional factors, and contextual level (environmental).

As evidenced above, many models of stuttering center around the integration of various factors. Another such model, CALMS [21] is a framework for understanding the interconnected elements that influence stuttering. This model suggests that stuttering is influenced not only by motor issues, but also how people think and feel about themselves and their stuttering. Those perceptions, feelings, and attitudes have a direct impact on how well the message will be formulated and produced physiologically while conversing with a variety of communicative partners in a variety of communication situations. The converse holds true such that the communicative motor, linguistic, and social messages of the individual will impact upon the thought, perceptions, feelings, and attitudes regarding the communicative experiences one engages. All five components will uniquely combine in individuals to have variable degrees of influence on the frequency, type, and duration of stuttering. These five components form the underlying roots of the disorder and any assessment of stuttering should include a thorough measurement of each component. The " $\mathrm{C}$ " in CALMS refers to Cognitive, the thoughts, perceptions, awareness, and understanding of stuttering-all which can be either negative or positive. Awareness of stuttering, positive or negative, can be a vital contributor to stuttering. The " $\mathrm{A}$ " is for Affective: thoughts that are directly connected with feelings, emotions, and attitudes that accompany stuttering and communication in general. Thoughts and feelings are hard to separate and are vital to precipitating and maintaining stuttering. "L" is for Linguistic: the patient's language skills and abilities. Linguistic complexity influences fluency. Variations in language formulation demand can precipitate changes in the frequency and form of dysfluencies. The 
"M" stands for Motor, the frequency, type, duration, and severity of stuttering, as well as, secondary coping behaviors and overall speech motor control. The "S" represents Social, which is a person's communicative competence relative to reactions the client has to various communicative partners in a variety of speaking situations.

Most researchers investigating stuttering now agree that stuttering cannot be explained by a single-factor theory. More recently, Smith and Weber [22] advanced a multifactorial, dynamic account of the complex, nonlinear interactions of motor, linguistic, and emotional factors that contribute to the onset and development of stuttering $[20,23]$. Reviewing evidence related to how stuttering develops, including genetic/epigenetic factors; motor, linguistic, and emotional features; and advances in neuroimaging studies, these investigators state that, while stuttering ultimately reflects impairment in speech sensorimotor processes, its course over the life span is strongly conditioned by linguistic and emotional factors. In other words, rapid changes in many neurobehavioral systems are ongoing, and critical interactions among these systems likely play a major role in determining persistence of or recovery from stuttering [22].

\section{Genetics}

Most parents who come for a stuttering consultation have heard or deduced from their own family history that stuttering "runs in families." Parents should be taught that unlike other genetic conditions like Down Syndrome or Cystic Fibrosis that have specific genetic etiologies, stuttering inheritance appears to be of a multifactorial polygenic inheritance pattern [24,25]. Multifactorial polygenic inheritance means that it is most likely that more than one gene difference in concert with environmental factors likely cause stuttering. Yairi [26] and Ambrose, Yairi, and Cox [25] found stuttering in the immediate families of $42-45 \%$ of children and $64-71 \%$ of extended families of the children. No family history was reported in $31 \%$ of families. The role of genetics in stuttering is also evident in studies of twin pairs in which one or both twins stutter. Godai, Tatarelli, and Bonanni [27] found many more concordant pairs of monozygotic than dizygotic twins who stuttered, indicating a strong genetic factor; however, the percentage of concordant monozygotic twins is less than $100 \%$, implicating environmental factors. Howie $[28,29]$ reported $63 \%$ concordance for monozygotic pairs and $19 \%$ for dizygotic pairs. Though a genetic test cannot be given to find out if someone has the genetic makeup that can manifest in stuttering on a person or their offspring, aggregation studies have been completed that help predict the recurrence risk for stuttering. Andrews et al. [30] found that for males who have ever stuttered, the risk of stuttering is $22 \%$ for their sons and $9 \%$ for their daughters. For females who have ever stuttered, it is $36 \%$ for sons and $17 \%$ for daughters. It is unknown what exactly is transmitted when a family member passes on stuttering. Yairi [31] proposes several possibilities: biochemical pathways, structural anomalies, brain processing, motor skills, and/or temperament. Each of these possibly-inherited traits has been investigated as a factor in stuttering.

In a review of the literature on the genetics of stuttering, Kraft and Yairi [32] indicated that there is support from a range of studies for a genetic perspective of stuttering, but that "no definitive findings have been made regarding which transmission model, chromosomes, genes, or sex factors are involved in the expression of stuttering in the population at large." However, studies have identified likely causative gene mutations linked to stuttering. Mutations to three genes (GNPTAB, GNPTG, and NAGPA) have been found to disrupt the signal that directs enzymes to their target location in the lysosome of the cell [33]. Drayna and Kang [33] found that gene mutations were present in close to $10 \%$ of cases of familial stuttering.

\section{"How long will it last?" and "Will it go away?"}

Like the question of stuttering etiology, inquiries regarding the child's future course with stuttering do not have a definite answer. Speech-language pathologists should supply parents with evidence-based information about the early demographics of stuttering and data research data that help clinicians predict a child's risk for persistence.

It has been well-established in literature that approximately $75 \%$ of children who stutter will undergo spontaneous recovery $[34,35]$. Children who are within their first three years of stuttering since their time of onset are in a critical time period for the possibility of complete recovery; once that critical period of three to four years past onset has passed, a child is considered to have persistent stuttering [36]. Most cases begin from 20-48 years of age, mean of 34 months. As months go by after onset, the changes for recovery are diminished, such that the chance for recovery after two years is $47 \%$ and only $16 \%$ after three years [35]. In the Illinois Longitudinal Studies of children followed from close to their time of onset [37] $68 \%$ of children recovered without treatment within a period of two years. By 2 years after the initial evaluation, exactly $33 \%$ of 
each of the treated and untreated groups continued to stutter, and $67 \%$ of each of the groups had completely recovered [38]. Within a six-month period, $63 \%$ had improvement: $19 \%$ were judged as recovered, and $44 \%$ were judged as "possibly" recovered [36]. Andrews [39] determined that $75 \%$ of the risk of stuttering is over by age six. Further research suggests that $90 \%$ of the risk is over by age four, with very few onsets after age four [40].

\section{Prediction factors}

Longitudinal studies have allowed to researchers to tease out key differences between groups of children who tend to undergo spontaneous recovery with their stuttering versus children who tend to have persistent stuttering. The following are factors determined by the Illinois Longitudinal Studies to be key factors in predicting a child's risk for stuttering persistence [35]:

\section{Family history}

A family history of stuttering is the greatest predictive factor of stuttering persistence. A child has a $65 \%$ chance of following the path of his or her relatives who stutter in persistence or recovery.

\section{Gender}

Boys are at a higher risk for both incidence and persistence of stuttering. Girls tend to recover faster than boys who recover.

\section{Age at onset}

Persistence is associated with later age at onset, an average of 3.5 months later than those who recover with a large overlap. Awareness of disfluencies is sharply heightened between ages four and five.

\section{SLD trends}

\section{The critical period}

A very large proportion of children recover in the first three years following onset with some recovering in the fourth year of stuttering. The stuttering of children who recover is characterized by a decrease in the frequency of stuttering-like dysfluencies (SLDs) demonstrated in the first year. Children who persist tend to have a fairly stable SLD level after onset. A critical prognostic indicator for persistence was the steady use of stuttering-like disfluencies across the first year after onset, while children whose use stuttering-like disfluencies decreased over the first year tended to recover [35].

\section{Duration of stuttering history}

The longer the stuttering history beyond the first year, the higher the risk is for persistence, especially for girls (though recovery should not be ruled out). A child who has been stuttering for three to four years should be considered persistent, even if he or she exhibits mild stuttering.

\section{Disfluency length \\ Extent and duration}

Severity is not a predictor in very early stage stuttering. The continuing presence of disfluencies with more than one repetition unit, especially those containing three or more units per instance, is a sign of high risk. In the first year of treatment, a child should exhibit a reduction in the number of repetition units and the number of SLDs. If the disfluencies are present but shorter, prognosis is more positive. Children who recover naturally and early do not continue to exhibit multiple repetitions. The duration of disfluencies does not differentiate the persistent or recovered groups at any point in time.

\section{Sound prolongation and blocks}

The presence of sound prolongations and blocks are not a distinguishing feature close to onset; however, if the percentage of sound prolongations grows over time, so does the risk for persistence.

\section{Head and neck movements}

Secondary movements of the head and neck are not a good predictor of stuttering persistence shortly after onset; however, these movements had a sharp decrease in the first few months following onset in children who recovered. Children who did not have a significant decline in secondary movements of the head and neck tended to persist.

\section{Phonological skills}

Near onset, children who eventually persist show lower level phonological skills than those who recover- marginally lower than normative expectations. During the second year following onset, the phonological skills across children tend to "even out" between the persistent and recovered groups.

\section{Expressive language skills}

Very young children who stutter tend to demonstrate expressive language skills at or above the average range. Though this trend was found among children who stuttered compared to fluent peers, language abilities did not significantly distin- 
guish the persistent or recovered group from one another for prognostic purposes [41,42].

\section{COUNSELING-BASED APPROACHES FOR ADDRESSING RISK FOR STUTTERING PERSISTENCE}

It is important for parents to understand that if a child has been stuttering for longer than three years, their stuttering is considered persistent [36]. Many parents hold onto a view that their child may still outgrow his or her stuttering, even when they have been stuttering for longer than three years. Though improvements can be made through therapy, persistent developmental stuttering is a life-long condition that cannot be completed "fixed" through therapy. Several strategies may be employed to help parents cope with the difficult conversation about predicting the child's risk for persistent stuttering, including elements of Motivational Interviewing, Rational Emotive Behavioral Therapy, Beck's Scaling Questions, and Beck's Coping Questions.

\section{Normalizing}

This Motivational Interviewing technique is used to communicate to the parent that ambivalence and resistance to change are natural feelings that most people experience. Normalizing helps the patients to feel like they are not alone in their struggles with change. A clinician may say, for example, "Many parents struggle to process the fact that their child's stuttering may persist," or "In my experience, most parents experience some guilt that they did not detect that their child was stuttering sooner; that does not mean that the child is beyond help."

\section{Ellis' Rational Emotive Behavior Therapy (REBT)}

This counseling approach addresses the belief system. Ellis [43] theorized that people become afraid and upset during stress because we tend to reason in "absolute musts": "Awfulizing" with the parent helps to explore these beliefs and challenge them, which tends to cut down the intensity of the feeling. People remain attached to irrational beliefs. The clinician directly confronts the parent's belief system. Uses the ABC formula to demonstrate the sequence of events related to the development of irrational beliefs. A-Objective Event, B- Person's interpretation of the event, C- Emotional/behavioral reaction to the event. The clinician challenges the parent in the disputing process involving the parent's beliefs. Four steps: 1) Identify self-limiting beliefs, 2) Attempts to validate those be- liefs, 3) Realize they cannot be validated, 4) Replace them with more rational views. For example, if a parent is crying because they caused their child to stutter, a clinician may "awfulize" with the parent by saying, "Yes, I can see how you caused your child to have aberrant neurologic function, a unique genetic makeup, and above average language skills," to help him or her see that these feelings are irrational.

\section{Scaling questions}

Counselors may ask the parents to assess their situations by gaging their feelings or understanding. The clinician might ask: "On a scale of 1 to 10 , with 1 being that you feel hopeless about your child's communication outlook and 10 being you feel like your child has a great shot at being a satisfied communicator, how do you feel about what we were discussing about his future communication abilities."

\section{Coping questions}

When faced with overwhelming problems, may parents do manage to press on with daily tasks, even when these things can pose great difficulty. Asking about how a patient is coping is a powerful reminder about their strength and in dealing with adversity. A speech-language pathologist may ask: "How have you managed to keep him so confident and willing to talk to other people?".

When it comes to children who are within their first few year of stuttering after onset, treatment is aimed at reducing SLDs in hopes of promoting recovery. In children whose recovery is unlikely, the focus of treatment is teaching functional strategies to produce fluent speech and positively approach communication. The goal of therapy with persistent developmental stuttering is not to make the stuttering go away permanently, rather to give the child a new way of speaking that can be used as a tool to be more fluent and to make the child a well-adjusted, empowered communicator.

In young children who may not always be able to employ speech strategies and to demonstrate behavioral changes needed to create fluent speech, changing the child's environment is key in recovery. Known what causes children to stutter more highlights useful steps that can be taken to change the environment to help a child to become more fluent. Children tend to stutter more when they speak at a fast rate, when they are engaging in complex linguistic tasks like story-telling, and when they feel under pressure. Thus, slowing down the pace of activities and the rate of parental speech, reducing linguistic demands, and lessening outside pressure or anxiety 
can help a child to become a more fluent speaker. Gregory [44] proposes the following environmental considerations when counseling families of children who stutter as ways to help young children achieve more fluent speech:

\section{Building and maintaining a child's self-esteem}

The way a child feels about himself/herself is vital to their success in therapy. The period of time of stuttering onset and early childhood stuttering can negatively impact the parentchild relationship during critical years when a child is developing self-esteem. Developing a better parent-child relationships can have bidirectional benefits as the children and the parents appreciate one another's attention. Child-centered therapy-allowing children to choose activities and play in a relaxed manner- helps children to build self-confidence; clinicians discussing and asking about what is happening in the child's speech during these interactions helps the child feel like the clinician has insight into the mystery of their problems. It is often a good idea to call stuttering what the child calls it; letting the child describe their own complaint helps them to understand it, rather than supplying the label for them.

\section{Sibling relationships}

Older siblings of parents may place undue linguistic pressure on children during speech interactions. Younger siblings may draw attention away from the child who stutters. Parents may feel like they can have certain types of interactions with one child more than another sibling. Strategies for managing turntaking and spending individual time with each child can help reduce pressure and anxiety in home communication interactions.

\section{Working with extended family}

Extended family members who spend considerable amounts of time with the parents should be educated with ways that they can be involved in helping promote therapy targets. For example, a grandmother who plays excitedly with her grandson who stutterers can be taught more relaxed ways to interact with him.

\section{Approaches for addressing environmental changes}

Teaching parents about environmental changes to promote fluency can bring about the stress of changing their lifestyle and feelings of pressure to be successful with implementing the suggestions. Many counseling approaches may be helpful in helping parents cope with employing environmental changes: elements of Motivational Interviewing, elements of Beck's Cognitive Behavioral Therapy, brainstorming, and goal-setting.

\section{Decisional balancing}

This element of Motivational Interviewing is an exercise entails the parents completing self-assessments about their actions, listing good and bad things about each. The point of decisional balancing is that parents realize that they get some desirable results from resisting change or from problem behaviors and there will be sacrifices if they change their behavior. Decisional balancing exercises can be done formally having patients write out good and "less good" attributes about their actions, or counselors can informally ask the patients open-ended questions about their problem behavior and their self-assessments of their good and bad behaviors. For example, a clinician may ask, "What are some of the positive things that come from slowing down the pace of play activities at home?".

\section{Statements supporting self-efficacy}

This Motivational Interviewing technique involves the counselor getting the parent to address the positive changes that they have made in order to increase their self-confidence. When patients give self-recognition to their efforts to create change, they gain confidence that can help spur them along with future actions. The counselor shows the parent that they are ready and able to make the changes that they need to make. The clinician may say, "I see that you have make progress with modeling a slowed rate of speech. How were you able to do that?".

\section{Affirmations}

This Motivational Interviewing technique is manifested in statements used by counselors to show that they recognize the parent's progress and efforts to change. The counselor makes comments that acknowledge the parent's work without sounding like a "cheerleader," (e.g., "I knew you could do it." "That's wonderful!, etc.) Counselors should make an effort to make these statements sound heartfelt. Affirmations may be stated like, "Your hard word shows by how confident he is when he speaking to unfamiliar listeners."

Brief Solution Focused Therapy [45] offers some specific techniques that can be used the help parents with environmental strategy follow-through. One method is referred to as 
“Looking for previous solutions." Most parents have previously solved many problems and probably have some ideas of how to solve their child's present problem. The objective of looking for previous solutions is to help parents see these potential answers. Good questions to facilitate this thought process: "Are there times when this has been less of a problem?" "What did you do that was helpful?" Brief Solution Focused Therapy also uses "looking for exceptions."

An exception is something that happens instead of the problem, sometimes unintentionally. Many parents have experienced exceptions to their problem, even if they have no prior experience with a solution. Find out when their problem could have occurred but did not. A good question for this thought process: "What is different about the times when this is less of a problem?" Compliments are another part of de Shazer and Berg's approach. Compliments validate what the parent is already doing well. Acknowledging how difficult a parent's problems are encourages the parent to change and sends the message that the clinician cares about and has been listening to the parent. Compliments can be delivered in the form of appreciatively toned questions: "How did you do that?". Invite the parent to self-compliment by virtue of answering the question. Inviting the parents to do more of what is working is another important strategy with Brief Solution Focused Therapy. Encouraging the parent to do more of what is working, what has previously worked, or to keep taking steps to make their future visions a reality helps them the see their abilities to solve their problems positively. This invitation gently encourages the parent to do more of what has previously worked or to try changes they have brought up which they would like to try.

\section{Brainstorming}

This technique [46] involves inviting the parent to problemsolve and trouble-shoot situations together. A clinician and parent may start by producing as many ideas as possible, use one idea as a takeoff point for others, get rid of normal constraints to thinking, and produce even more ideas for clarifying ideas on the list. For example, a clinician and parent may list all of the possible strategies that they can come up with for managing turn-taking among a patient's siblings at the dinner table.

\section{Goal-setting}

Discussing goals with the parent is vital in early stages of therapy with adults and school-aged parents [46]. Setting goals to- gether helps the parent to make informed choices about action plans. An important goal of treatment in early childhood stuttering treatment is to help parents become home therapists.

\section{Approaches for addressing treatment}

Despite going over the risk factors for persistent stuttering, some parents may need encouragement that their child's condition would be best managed with therapy. Getting parents to consider seeking therapy without scaring them into the decision can be a delicate process warranting counseling skills on the part of the speech-language pathologist. Some of proposed techniques are discussed below.

\section{Eliciting/evoking change talk}

This Motivational Interviewing technique involves the counselor getting the parent to talk about positive outcomes to their child's stuttering so that the parent will start thinking about reasons to consider making change (seeking therapy). Evoking these thought processes from parents helps them to see the differences between their words and their actions. Rather than the counselor lecturing the parent about how they need to change, the counselor helps the person to arrive at that conclusion on his or her own. A clinician may ask, "What would be the ideal result of you making an effort to bring her to therapy?" Provoking extremes can be a tool in change talk to help patients see the need for change. For example, "What is the worst thing that might happen if you don't get him speech therapy?".

\section{Columbo approach}

This technique is a Motivational Interviewing tool in which the counselor brings up the discrepancies in a parent's behaviors. The counselor engages in a curious inquiry about juxtaposing behaviors to highlight them for the parent in a way this is not confrontational or judgmental. The counselor addresses behaviors that are not in line with the patient's statements about what they want to point out these differences but avoids defensiveness on the part of the parent. These questions may be phrased, "On the one hand you say you want her stuttering to improve as soon as possible. But on the other hand you are saying that you just can't make time for speech therapy right now? What do you think is causing the problem?".

\section{Egan's three-stage skilled-helper model}

This counseling approach [47] is interactive method that can 
be used for helping parents to clarify their problems and to systematically select a plan of action for changing their situation. The first stage is the current scenario. In this stage the parent feels enabled to tell his or her side of the story with enough detail in order for the clinician to full understand the current scenario. This processed is aided by the clinician helping the parent to recognize any "blind spots" that prevent them from seeing the problem more clearly. In the scenario that a parent is denying the need for speech therapy, the clinician can hear the parent out on all of their reasons behind not wanting to begin speech therapy without judgment. The preferred scenario stage, stage two, is about helping the parent to see what he or she needs to do to have a better outcome. Clinicians should not assume that the parent knows the best outcome or think that the best scenario is implied. In the third and final action strategies stage the parent and clinician focus on developing strategies for taking action and the activities the parent will need to do to get what he or she wants. In the final stage the parent must act on his or her own behalf and choose to take action to change their situation. The clinician can try to help the parent arrive at the choice of seeking speech therapy for their high-risk child, but speech pathologists cannot force parents' hands.

\section{CONCLUSIONS}

The sheer number of publications over several decades addressing the issue of parent counseling during the initial evaluation of preschoolers who stutter indicates a wide spread, long sustained belief in the importance of this clinical feature. However, at present, less than adequate opportunities are afforded our future clinicians to hone this important clinical skill. It is necessary for university training programs to develop educational and clinical training for students in order to meet minimum knowledge and skills competencies in the area of stuttering in an effort to increase their knowledge and comfort levels [48]. To be included in this training should be the various aspects of parent/caregiver counseling and information sharing during the preliminary stages of the therapeutic process. It is incumbent on academic training programs, and indeed, the profession as a whole, to identify alternative ways of preparing student clinicians to appropriately and effectively work with young children who stutter and their families [49]. If such efforts are not undertaken, and if the apparent trends identified in the area of pediatric fluency disorders continue, then it is likely that the number of clinicians who are qualified to help children who stutter will decrease even further. Refining the way speech-language pathologists answer these questions will evolve with strides in stuttering research and the willingness of professionals to borrow counseling strategies from across disciplines. This interdisciplinary approach may very well aide in a more comprehensive approach to counseling in fluency disorders. Though countless stuttering researchers are devoted to uncovering more information about etiology and predictive factors, a focus on applying counseling-based delivery of this information is warranted. When it comes to a conversation about a child's stuttering, the dialogue is not just about what is said, but also, how it is said.

\section{REFERENCES}

1. Johnson W. Stuttering. In W. Johnson, S. Brown, J. Curtis, C. Edney, J. Keaster, editors. Speech handicapped school children. New York: Harper \& Row; 1948. p. 179-257.

2. Johnson W. Stuttering and what you can do about it. Minneapolis: University of Minnesota; 1961.

3. Schuell H. Working with parents of stuttering children. Journal of Speech and Hearing Disorders. 1949;14:251-254

4. Zwitman D. The disfluent child. Baltimore: University Park. 1978.

5. Gregory H, Gregory CB. Counseling children who stutter and their parents. In: R.F. Curlee editors. Stuttering and related disorders of fluency. New York: Thieme. 1999. p43-63.

6. Rustin L, Botterill W, Kelman E. Assessment and therapy for young disfluent children: family interaction. London: Whurr; 1996.

7. Starkweather CW. Current trends in therapy for stuttering children and suggestions for future research. ASHA Reports. 1990;18: 82-90.

8. Zebrowski PM, Schum R. Counseling parents of children who stutter. American Journal of Speech Language Pathology. 1993;2: 65-75.

9. Manning W. Clinical decision making in fluency disorders. New York: Delmar Cengage Learning; 2001.

10. Rogers C. Client-centered therapy: its current practice, implications and theory. London: Constable; 1951.

11. Orton S. Reading, writing and speech problems in children. New York: W.W.Norton \& Co; 1937.

12. Van Riper C. The Nature of Stuttering. New Jersey: Prentice-Hall; 1971.

13. Postma A, Kolk H. The covert repair hypothesis: Prearticulatory repair processes in normal and stuttered disfluencies. Journal of Speech and Hearing Research. 1993;36:472-487.

14. Conture E, Louko L, Edwards ML. Simultaneously treating childhood stuttering and disordered phonology: experimental therapy, preliminary findings. American Journal of Speech-Language Pathology. 1993;2:72-81.

15. Yaruss JS, Conture EG. Stuttering and phonological disorders in children: examination of the Covert Repair Hypothesis. Journal of 
Speech and Hearing Research. 1996;39:349-364.

16. Ambrose N, Cox N, Yairi E. The genetic basis of persistent and recovered stuttering. Journal of Speech, Language, and Hearing Research. 1997;40:567-580.

17. Starkweather CW. The effectiveness of stuttering therapy: An issue for science? 1999. In N.B. Ratner, E.C. Healey editors. Stuttering research and practice: bridging the gap. New Jersey: Lawrence Erlbaum; 1999;231-244.

18. Zimmerman G. Stuttering: a disorder of movement. Journal of Speech and Hearing Research. 1980;23:122-136.

19. Wall M, Meyers F. Clinician management of childhood stuttering. Baltimore: University Park Press; 1984.

20. Smith A, De Nil. Stuttering: A unified approach to a multifactorial, dynamic disorder. In N.B. Ratner, E.C. Healey editors. Stuttering research and practice: Bridging the gap. New Jersey: Lawrence Erlbaum; 1999.

21. Healey E, Trautman L, Susca M. Clinical applications of a multidimensional model for the assessment and treatment of stuttering. Contemporary Issues in Communication Science and Disorders. 2004;31:40-48

22. Smith A, Weber C. How stuttering develops: the multifactorial dynamic pathways theory; 2017.

23. Smith A, Kelley E. Evidence-based treatment and stuttering: historical perspective. Journal of Speech, Language, and Hearing Research; 1997.

24. Kidd K. Genetic models of stuttering. Journal of Fluency Disorders. 1980;5:187-201.

25. Ambrose N, Yairi E, Cox N. Genetic aspects of early childhood stuttering. Journal of Communication Disorders. 1993;35:63-82.

26. Yairi, E. The onset of stuttering in two- and three-year-old children. Journal of Speech and Hearing Disorders. 1983;48:171-177.

27. Godai U, Tatarelli R, Bonanni G. Stuttering tics in twins. Acta Geneticae Medicae et Gemellologiae. 1976;25:369-375.

28. Howie P. Concordance for stuttering in monozygotic and dizygotic twin pairs. Journal of Speech and Hearing Research. 1981;24: 317-321.

29. Howie P. Intrapair similarity in frequency of disfluency in monozygotic and dizygotic twin pairs containing stutterers. Behavioral Genetics. 1981;11:227-238.

30. Andrews G, Craig A, Feyer A, Hoddinott S, Howie P, Neilson M. Stuttering: a review of research findings and theories circa 1982. Journal of Speech and Hearing Disorders. 1982;48:226-246.

31. Yairi E. Speech characteristics of early childhood stuttering. In R. Curlee, G. Siegel editors. Nature and treatment of stuttering. Needham Heights, MA: Allyn and Bacon; 1997.

32. Kraft SJ, Yairi E. Genetic bases of stuttering: the state of the art. Fo- lia Phoniatrica et Logopaedica; 2011.

33. Drayna \& Kang. Genetics of speech and language disorders. Annual Review of Genomics and Human Genetics; 2011.

34. Yairi E, Ambrose N. Spontaneous recovery and clinical trials research in early childhood stuttering: a response to Onslow and Packman. Journal of Speech, Language, and Hearing Research. 1999;42:402-410.

35. Yairi E, Seery C. Stuttering: foundations and Clinical Applications. Pearson; 2015.

36. Yairi E, Ambrose N, Niermann R. The early months of stuttering: a developmental study. Journal of Speech and Hearing Research. 1993;36:521-528.

37. Ryan B. A longitudinal study of articulation, language, rate, and fluency of 22 preschool children who stutter. Journal of Fluency Disorders. 2001;26:107-127.

38. Yairi E, Ambrose N. A longitudinal study of stuttering in children: a preliminary report. Journal of Speech and Hearing Research. 1992a;35:755-760.

39. Andrews G. The epidemiology of stuttering. In R.F. Curlee, W.H. Perkins editors. Nature and treatment of stuttering. San Diego: College-Hill Press; 1984.

40. Mansson H. Childhood stuttering: incidence and development. Journal of Fluency Disorders. 2000;25:47-57.

41. Watkins R, Yairi E. Language production abilities of children who persisted and recovered from stuttering. Journal of Speech, Language, and Hearing Research. 1997;40:385-399.

42. Watkins R, Yairi E, Ambrose N. Early childhood stuttering III: initial status of expressive language abilities. Journal of Speech, Language, and Hearing Research. 1999;42:1125-1136.

43. Ellis A. Rational emotive behavior therapy: it works for me-it can work for you. Amherst, NY: Prometheus Books; 2004.

44. Gregory H, Campbell J, Gregory C, Hill D. Stuttering therapy: rationale and procedures. Boston: Allyn and Bacon; 2003.

45. De Shazer S, Berg IK. Making numbers talk: language in therapy; 1993.

46. Bennett E. Working with people who stutter: a lifespan approach. New York: Pearson; 2005.

47. Egan G. The skilled helper: a problem management approach to helping. New York: Brooks Cole; 1998. p. 6.

48. Santus N, Tellis G, Kong. F. Are graduate students receiving adequate education and training in fluency disorders? Clinical Archives of Communication Disorders. 2019;4:236-251.

49. Gregg, B. Initial counseling with parents of preschoolers who stutter: enhancing graduate students' skills using simulated caregivers. Perspectives on Fluency and Fluency Disorders. 2013;23:2129. 